\title{
Cesium-13l brachytherapy in high risk and recurrent head and neck cancers: first report of long-term
} outcomes

\author{
Anthony Pham, BS', Shruthi Arora, MD', A. Gabriella Wernicke, MD, MSc', David I. Kutler, MD³, Marc Cohen, MD³, \\ William Kuhel, MD³, Samuel Trichter, MS', Dattatreyudu Nori, MD', Silvia C. Formenti, MD', Bhupesh Parashar, MD' \\ 'Weill Cornell Medical College, New York, NY, ${ }^{2}$ Stich Radiation Center, New York-Presbyterian/Weill Cornell Medical Center, New York, NY, \\ ${ }^{3}$ Division of Otolaryngology, New York-Presbyterian/Weill Cornell Medical Center, New York, NY, USA
}

\begin{abstract}
Purpose: The feasibility and efficacy of re-irradiation using contemporary radiation techniques to treat recurrent head and neck cancer has been demonstrated but the role of brachytherapy is unclear. Here we describe the use of ${ }^{131} \mathrm{Cs}$ brachytherapy with concurrent salvage surgery in 18 patients.

Material and methods: Eligible patients underwent maximal gross resection of the tumor with implantation of brachytherapy seeds delivering a minimum dose of $80 \mathrm{~Gy}$ to the tumor bed. Rates of overall survival, locoregional progression free survival, disease-free survival, and radiation-induced toxicity were analyzed.

Results: Retrospective Kaplan-Meier analysis shows median overall survival was 15 months and disease free survival was 12 months. Two patients developed grade 3 toxicity; all other complications were grade 1-2 with no grade 4 or 5 complications.

Conclusions: Compared to prior literature, our study shows comparable rates of survival with a decreased rate of radiation-induced toxicity.

Key words: ${ }^{131} \mathrm{Cs}$, brachytherapy, head and neck cancer, recurrence.

\section{Purpose}

Locoregional recurrences (LRR) of head and neck $(\mathrm{HN})$ cancers are common and are difficult to treat. Progression of disease following recurrence is rapid, resulting in significant morbidity and mortality [1, 2, 3, 4, 5]. Optimal treatment of LRR is not been clearly defined due to complex factors, such as previous radiation (RT) treatment, tumor recurrence site, and performance status. Surgical resection of LRR is usually considered the standard of care $[6,7,8,9,10,11]$. However, resection can be complicated by anatomic proximity to critical structures and primary treatment effects. In addition, salvage surgery alone has suboptimal outcomes for LRR of HN cancer with reported 5-year overall survival (OS) ranging from $11-39 \%$ and grade $\geq 3$ complications ranging from $5-48 \%$ $[12,13,14]$. For unresectable tumors, chemotherapy (CT) or salvage external beam radiation therapy (EBRT) is considered, although response rates are poor with majority of patients dying within months [15].

Historically, salvage RT has been avoided in previously irradiated patients due to concerns about intolera- ble toxicity, including cerebrovascular accidents, carotid rupture, and skin and spinal cord necrosis [16]. Recent studies have shown the feasibility and effectiveness of re-irradiation using contemporary treatment techniques and delivery methods [17]. Despite this, there is no consensus on practical clinical and technical guidelines for the treatment of recurrent head and neck cancers.

Brachytherapy has been shown to be a promising treatment modality in the treatment of recurrent head and neck cancer achieving excellent local control even in the unresectable setting to deliver curative doses [18, $19,20,21]$. Unlike EBRT, brachytherapy is able to deliver a high-localized dose with relative sparing of critical normal tissues due to rapid tissue falloff [22]. Although a high rate of local tumor control with limited morbidity can be achieved with brachytherapy [23, 24, 25, 26], there is no consensus about the role brachytherapy for LRR in HN cancers. Recognizing the need for further investigation, we initiated a program of salvage surgery with intraoperative brachytherapy using ${ }^{131} \mathrm{Cs}$ implants, a novel radioisotope with unique radiobiologic and dosimetric properties. Here we describe the incidence of radiation-induced 
toxicity, locoregional control (LRC), and OS in the first 18 patients (20 implants) undergoing ${ }^{131} \mathrm{Cs}$ implantation for recurrent head and neck cancer.

\section{Material and methods}

The study was an IRB approved retrospective analysis of patients treated with ${ }^{131} \mathrm{Cs}$ brachytherapy in $\mathrm{HN}$ cancers (\#0511008245).

\section{Patient and tumor characteristics}

Patients that were included were recurrent biopsyproven HN cancers, patients with a new cancer of the $\mathrm{HN}$ arising within previously irradiated fields or patients without prior RT but refused EBRT at the initial consultation. None of the patients had evidence of active distant metastatic disease (DM).

\section{Surgery}

A multidisciplinary team of radiation oncologists, medical oncologists, and HN surgeons coordinated patient care and evaluated patients prior to treatment. If the recurrent tumor was deemed resectable, a gross total resection of the tumor with implantation of the tumor bed with brachytherapy seeds was attempted (Figure 1). Immediate reconstruction was performed by a plastic surgeon if necessary.

\section{Intraoperative brachytherapy}

In patients who underwent resection, ${ }^{131} \mathrm{Cs}$ brachytherapy seeds were implanted at $0.5-1 \mathrm{~cm}$ distance, making sure that the tumor bed was covered by $80 \mathrm{~Gy}$ at $0.5 \mathrm{~cm}$ using a nomogram created in Variseed (Varian Medical System, Palo Alto, CA, USA) [27]. Median seed activity was $2.4 \mathrm{U}(0.5 \mathrm{mCi} / \mathrm{s})$. Median seed air kerma strength was $2.4 \mathrm{U}$ (3.77 mCi apparent activity). Post implant dosimetry was analyzed using BrachyVision software (Varian Medical Systems, Palo Alto, CA, USA). The dosimetry and exposure rate have been previously reported by our institution in a prior study, with excellent dosimetric coverage and acceptable exposure rate to treating physicians and staff [23].

Briefly, after the resection of the tumor that needs to be implanted, the tumor bed (Clinical Target Volume-CTV) is identified and a ${ }^{131} \mathrm{Cs}$ plaque (Figure 1) is placed on the

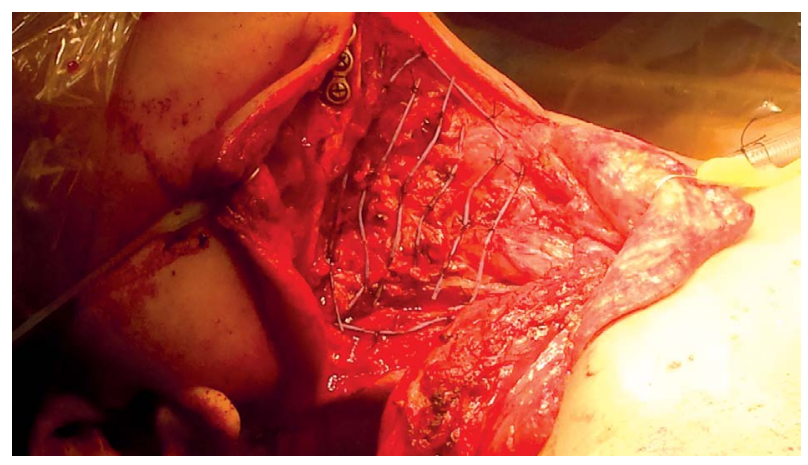

Fig. 1. Implantation of tumor bed with ${ }^{131} \mathrm{Cs}$ mesh tumor bed (planer implant). The implant is placed so that it covers the entire tumor bed and an additional $0.5 \mathrm{~cm}$ around the tumor bed. This means that $\mathrm{V}_{100}$ (volume of CTV receiving $100 \%$ prescribed dose) is at $100 \%$. In addition, $\mathrm{D}_{90}$ (dose going to $90 \%$ clinical target volume) is also at least $100 \%$ of the prescription dose in all implants. As mentioned previously, our prescription dose was $80 \mathrm{~Gy}$. This technique of ${ }^{131} \mathrm{Cs}$ implant was performed as an open surgical procedure.

\section{Follow-up}

All patients were evaluated every 1-2 months by a radiation oncologist, medical oncologist, and/or a head and neck surgeon for the first 12 months, followed by evaluation every 3-4 months thereafter. Recurrence was evaluated by clinical examination and confirmed by contrast CT and/or FDG-PET.

\section{Toxicity assessment}

Acute toxicity and late complications were assessed retrospectively by reviewing all charts. All symptoms and complications that were documented in patient records during and following surgical resection with brachytherapy seed placement were recorded. Toxicity grading was according to the Radiation Oncology Toxicity Group criteria.

\section{Statistical methods}

Analysis was performed for toxicity, OS, locoregional progression-free survival (LRPFS), and disease free survival (DFS). The efficacy end points (OS, DFS, and LRC) were calculated from the date of the start of implantation to the date of the event. For OS, an event was death by any cause. For locoregional progression, an event was recurrence at the implantation site or development of regional node metastasis. For DFS, an event was locoregional failure, distant metastases, or death from another cause. Kaplan Meier analysis of OS, LRPFS, and DFS at 6, 12 and 18 months was performed. Toxicity was analyzed in a descriptive manner. SPSS software (IBM Corp. Armonk, NY, USA) was used for the statistical analysis.

\section{Results}

Between 2010 and 2013, a total of 18 patients with 20 implants were treated with surgical resection and ${ }^{131} \mathrm{Cs}$ brachytherapy. All patients were evaluated preoperatively with a history and physical examination, routine hematology and chemistry laboratories, axial imaging of the head and neck, and chest radiography. All patients were assessable for toxicity and overall efficacy.

Squamous cell carcinoma (SCC) was the most common histology (12/18). All but one patient had a history of prior radiation in the area of tumor recurrence. Prior definite EBRT dose prescription ranged from 50-70 Gy. One patient had gross residual disease following surgical resection. Two patients had microscopic margins positive for tumor, which the remaining patients had surgical margins free of tumor. Two patients underwent an addi- 
tional surgical resection and brachytherapy implantation 2 months and 5 months later for local recurrence that developed outside the treatment volume. Thirteen patients had previous LRR treated with surgical salvage therapy. Patient characteristics are shown in Table 1.

All patients were implanted with ${ }^{131} \mathrm{Cs}$ seeds. The prescribed median dose was $80 \mathrm{~Gy} 0.5 \mathrm{~cm}$ from the implant (range 80-100 Gy). This was the total lifetime dose from the implant. All brachytherapy implants were permanent except in one patient, in which the seeds were removed after 39 days. Dose volume histograms (DVH) of two represen- tative patients are shown in Figure 2. As shown in the figure, the most important and critical normal structure was the spinal cord, which received minimal radiation scatter.

Two patients developed grade 3 toxicity; all other complications were grade 1-2. No grade 4 or 5 complications were observed. The most common complications were dermatitis and hoarseness. Severe complications such as massive hemorrhage or cardiovascular accidents did not occur. A summary of the toxicity is shown in Table 2.

With a median follow-up of 38 months (total range 1-44 months), 11 patients developed another LRR of head-

Table 1. Patients characteristics

\begin{tabular}{|c|c|c|c|c|}
\hline $\begin{array}{l}\text { Patient/Age/ } \\
\text { Gender }\end{array}$ & Primary tumor site & Histology & Recurrence site/Implant site & Prior external radiation \\
\hline \multirow[t]{2}{*}{$1 / 69 / M$} & \multirow[t]{2}{*}{ Right buccal mucosa } & SCC & Submental node/Submental region & Yes, post-op RT, full dose RT \\
\hline & & SCC & Right chin/Right chin subcutaneous & Yes, post-op RT, full dose RT \\
\hline $2 / 22 / F$ & $\begin{array}{l}\text { Left anterior } 1 / \\
3^{\text {rd }} \text { tongue }\end{array}$ & SCC & Right neck/Right neck & Yes, CRT, 68 Gy \\
\hline $3 / 60 / F$ & Soft palate & SCC & $\begin{array}{l}\text { Residual disease on PETCT encasing } \\
\text { carotid/Right neck implant with gross } \\
\text { residual disease after resection }\end{array}$ & Yes, CRT, full dose RT \\
\hline $4 / 75 / F$ & Right parotid & SCC & Right parotid/Right parotid bed & Yes, post-op RT, 63 Gy \\
\hline $5 / 77 / M$ & Right parotid & $\begin{array}{l}\text { Merkel cell } \\
\text { carcinoma }\end{array}$ & Right preauricular node/Right neck & Yes, post-op RT, 63 Gy \\
\hline $6 / 82 / F$ & Right hard palate & SCC & Bilateral neck nodes/Bilateral neck & Yes, post-op CRT, full dose \\
\hline 7/71/M & Left nasal cavity & Carcinosarcoma & $\begin{array}{l}\text { Nasal cavity/Tumor bed after } \\
\text { endoscopic resection }\end{array}$ & $\begin{array}{l}\text { Yes, prior brain post-op } \\
\text { radiation } \times 2 \text { for resected } \\
\text { tumors }\end{array}$ \\
\hline $8 / 88 / M$ & Chest wall & SCC & $\begin{array}{l}\text { Supraclavicular/Tumor bed after } \\
\text { resection }\end{array}$ & Yes, post-op RT, 50 Gy \\
\hline $9 / 68 / F$ & $\begin{array}{l}\text { Left neck and } \\
\text { parapharyngeal } \\
\text { region }\end{array}$ & $\begin{array}{l}\text { High grade } \\
\text { sarcoma }\end{array}$ & Left neck/Left neck tumor bed & $\begin{array}{l}\text { Yes, prior mantle radiation } \\
\text { for Hodgkin's lymphoma }\end{array}$ \\
\hline \multirow[t]{2}{*}{$10 / 74 / M$} & \multirow{2}{*}{$\begin{array}{l}\text { Right temporal } \\
\text { region }\end{array}$} & \multirow{2}{*}{$\begin{array}{l}\text { Merkel cell } \\
\text { carcinoma }\end{array}$} & Right zygoma/Tumor bed & Yes, post-op RT, 60 Gy \\
\hline & & & Right parotid & Yes, post-op RT, 60 Gy \\
\hline $11 / 71 / M$ & Left tonsil & SCC & $\begin{array}{c}\text { Patient refused XRT after surgery/ } \\
\text { Left neck implanted }\end{array}$ & No, prior RT \\
\hline $12 / 66 / F$ & Left maxilla & $\begin{array}{l}\text { Osteosarcoma } \\
\text { (RT induced) }\end{array}$ & Skull base/Tumor bed & Yes, post-op RT, 63 Gy \\
\hline $13 / 69 / F$ & Left hard palate & SCC & Left neck node/Neck tumor bed & Yes, post-op RT, 54 Gy \\
\hline $14 / 83 / \mathrm{F}$ & $\begin{array}{l}\text { Right maxilla with } \\
\text { metastatic, } \\
\text { right neck node }\end{array}$ & SCC & Right neck and parotid/Right neck & Yes, post-op RT, full dose RT \\
\hline $15 / 68 / M$ & Nasopharynx & $\begin{array}{l}\text { Mucoepidermoid } \\
\text { carcinoma }\end{array}$ & $\begin{array}{l}\text { Nasopharangeal tumor/ } \\
\text { Nasopharynx bed }\end{array}$ & Yes, CRT, full dose RT \\
\hline $16 / 70 M$ & Left neck & SCC & Left neck nodes/Left neck & Yes, post-op RT, 63 Gy \\
\hline $17 / 62 / M$ & Tongue & SCC & $\begin{array}{c}\text { Base of tongue/Base of tongue } \\
\text { tumor bed }\end{array}$ & Yes, 66 Gy \\
\hline $18 / 46 / \mathrm{F}$ & Piriform sinus SCC & SCC & Hypopharyngeal/Right neck & Yes, post-op RT, full dose RT \\
\hline
\end{tabular}

Full dose RT - RT given at outside institution, no definite dose available but documents suggesting full dose RT, post-op RT - post-operative radiation therapy, $C R T$ - chemotherapy plus radiation therapy, SCC - squamous cell carcinoma 


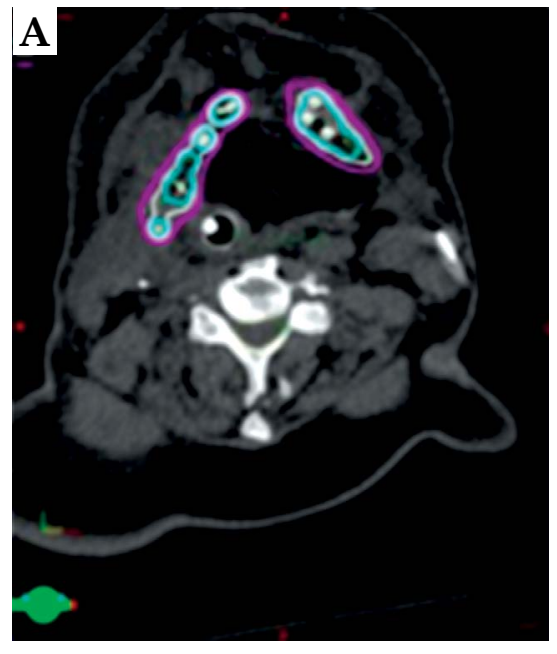

B Cumulative dose volume histogram
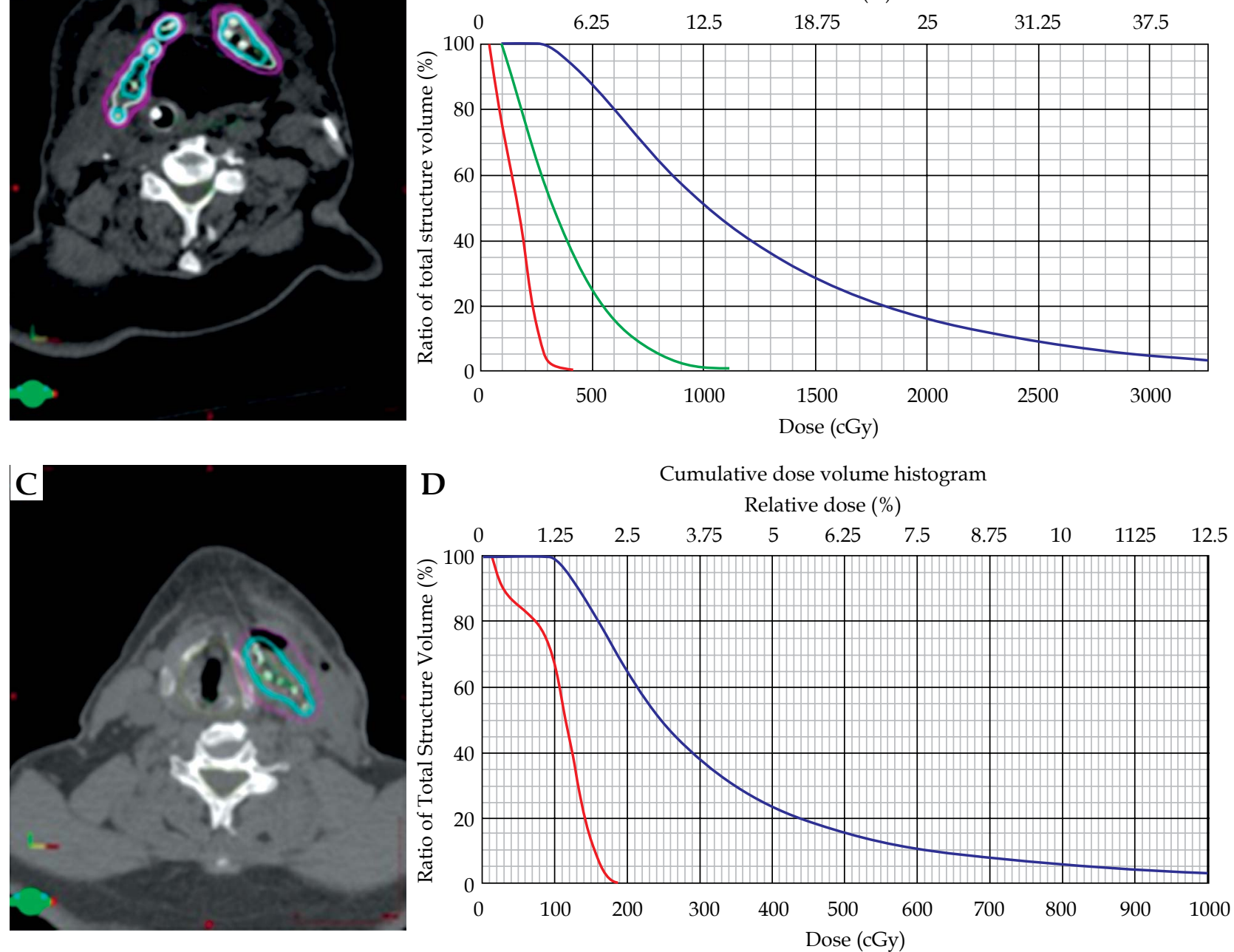

Fig. 2. A) Implant from patient \#17 with B) dose volume histograms (DVH). Maximum esophagus and spinal cord dose was 22.26 Gy and 19.26 Gy, respectively. C) Implant from patient \#13 with D) DVH. Maximum larynx, esophagus, and spinal cord dose was $53.43 \mathrm{~Gy}, 12.68 \mathrm{~Gy}$, and $4.24 \mathrm{~Gy}$, respectively

Table 2. Summary of toxicity due to brachytherapy and surgical resection

\begin{tabular}{llllll} 
Toxicity & \multicolumn{7}{c}{ Grade } & 5 \\
\hline Acute & 1 & 2 & 3 & 4 & 0 \\
\hline Mucositis & 2 & 0 & 0 & 0 & 0 \\
\hline Dermatitis & 3 & 1 & 1 & 0 & 0 \\
\hline Hearing loss & 0 & 1 & 0 & 0 & 0 \\
\hline Xerostomia & 2 & 0 & 0 & 0 & 0 \\
\hline Dysphagia & 2 & 0 & 1 & 0 & 0 \\
\hline Edema, larynx & 0 & 1 & 0 & 0 & 0 \\
\hline Hoarseness & 2 & 2 & 0 & 0 & 0 \\
\hline Fistula & 2 & 1 & 0 & 0 & 0 \\
\hline Nasal cavity/Paranasal sinus reactions & 1 & 0 & 1 & 0 & 0 \\
\hline Dyspnea & 0 & & 0 & 0 & 0 \\
\end{tabular}


Table 3. Summary of clinical status

\begin{tabular}{|c|c|c|c|c|c|c|}
\hline \multirow[t]{2}{*}{ Patient } & \multicolumn{2}{|c|}{ Clinical follow up } & \multirow[t]{2}{*}{ Resection margin } & \multirow{2}{*}{$\begin{array}{l}\text { Local } \\
\text { recurrence }\end{array}$} & \multirow{2}{*}{$\begin{array}{c}\text { Distant } \\
\text { metastasis }\end{array}$} & \multirow{2}{*}{$\begin{array}{l}\text { Time to failure } \\
\text { (months) }\end{array}$} \\
\hline & Status & Time (months) & & & & \\
\hline 1 & DWD & 24.33 & RO & Y & Y (lung) & 10.3 \\
\hline 2 & DWD & 16.23 & RO & Y & N & 5.27 \\
\hline 3 & DWD & 5.97 & RO & $\mathrm{Y}$ & $\mathrm{N}$ & 0.6333 \\
\hline 4 & ADF & 43.43 & R2 & N & N & - \\
\hline 5 & ADF & 44.37 & RO & N & N & - \\
\hline 6 & DWD & 2.77 & RO & Y & $\mathrm{N}$ & 1.5333 \\
\hline 7 & DDF & 14.43 & RO & $\mathrm{N}$ & N & - \\
\hline 8 & DWD & 12.27 & RO & N & Y (brain) & 11.87 \\
\hline 9 & ADF & 38.67 & RO & $\mathrm{N}$ & N & - \\
\hline 10 & DWD & 14.50 & RO & Y & Y (node) & 3.83 \\
\hline 11 & ADF & 24.30 & $\mathrm{R} 1$ & $\mathrm{~N}$ & N & - \\
\hline 12 & DWD & 8.80 & RO & Y & Y (bone) & 1.9 \\
\hline 13 & DWD & 12.20 & RO & $\mathrm{N}$ & Y (lung) & 1.4 \\
\hline 14 & AWD & 29.27 & RO & Y & $\mathrm{N}$ & 14.1 \\
\hline 15 & LTF & 0.97 & RO & $\mathrm{N}$ & $\mathrm{N}$ & - \\
\hline 16 & DDF & 1.00 & RO & $\mathrm{N}$ & $\mathrm{N}$ & - \\
\hline 17 & AWD & 12.17 & $\mathrm{R} 1$ & Y & $N$ & 5.2 \\
\hline 18 & DWD & 4.93 & RO & $\mathrm{N}$ & Y (Node) & 1.23 \\
\hline
\end{tabular}

$D W D$ - dead with disease, DDF-dead, disease-free, AWD - alive with disease, ADF-alive, disease-free, LTF-lost to follow-up, $N$ - no

and-neck cancer, including the patient who had gross residual disease remaining after attempted surgery. In 6 of these 11 cases, the failure was locoregional and in 4 patients, it was isolated distant failure. One patient was found to have simultaneous locoregional and distant progression of disease. A summary of clinical follow-up of all patients is shown in Table 3.

The median OS was 15 months and DFS was 11 months. The 6, 12, and 18 month OS rate in this study was $77 \%, 71 \%$, and $45 \%$ (Figure 3). The 6, 12, and 18 month LRPFS rate in this study in patients was $69 \%, 62 \%$, and $52 \%$ (Figure 4). The 6, 12, and 18 month DFS rate in this study was $57 \%, 45 \%$, and $37 \%$ (Figure 5 ).

For patients with SCC and had received prior radiation, median OS was 12 months, LRFS is 14 months and disease free survival was 5 months (Table 4). The 6, 12, and 18 month OS rate for these patients was 53\%, 53\%, and $21 \%$. The 6,12 , and 18 month LRPFS rate for these patients was $65 \%, 52 \%$, and $26 \%$. The 6,12 , and 18 month DFS rate in these patients was $47 \%, 24 \%$, and $9 \%$.

\section{Discussion}

Our results demonstrate that brachytherapy with ${ }^{131} \mathrm{Cs}$ as an intraoperative/adjuvant to surgical resection is feasible with low rates of acute toxicity. This is the first study investigated at the outcomes and toxicities of ${ }^{131} \mathrm{Cs}$ permanent implants for head and neck cancer.

For recurrent, operable head and neck cancer, salvage surgery is the treatment of choice [9]. Surgery before reRT and chemotherapy for recurrent squamous-cell head

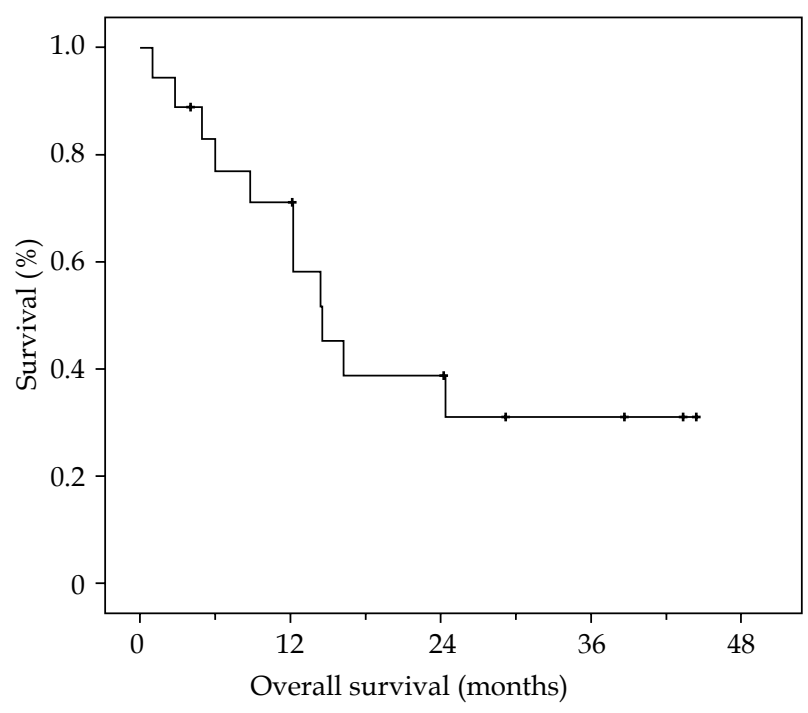

$\begin{array}{llllllll}\text { Number at risk } & 13 & 12 & 9 & 6 & 3 & 2 & 2\end{array}$

Fig. 3. Overall survival in entire patient population $(n=18)$ 


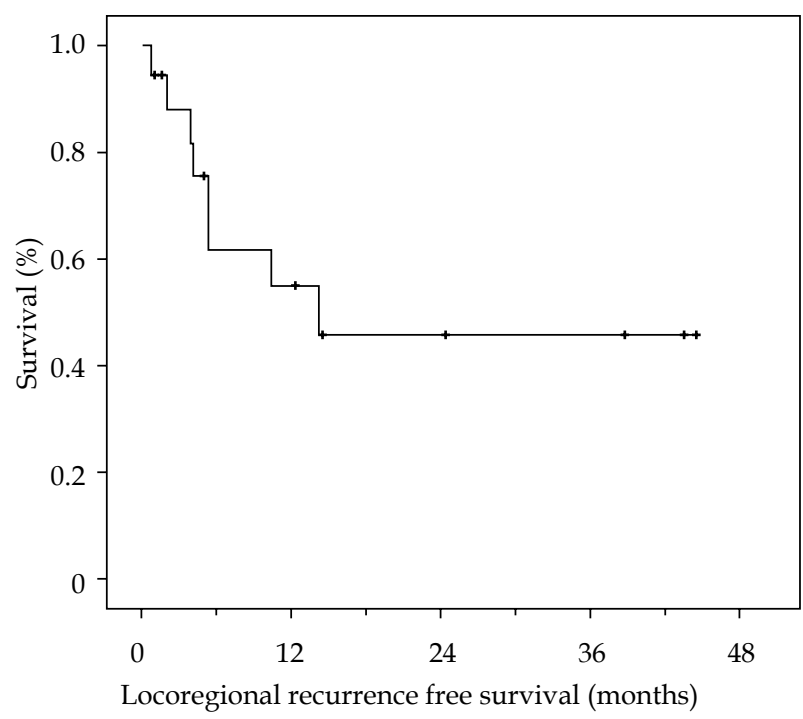

$\begin{array}{llllllll}\text { Number at risk } & 8 & 6 & 4 & 4 & 3 & 3 & 2\end{array}$

Fig. 4. Locoregional progression free survival in entire patient population $(n=18)$

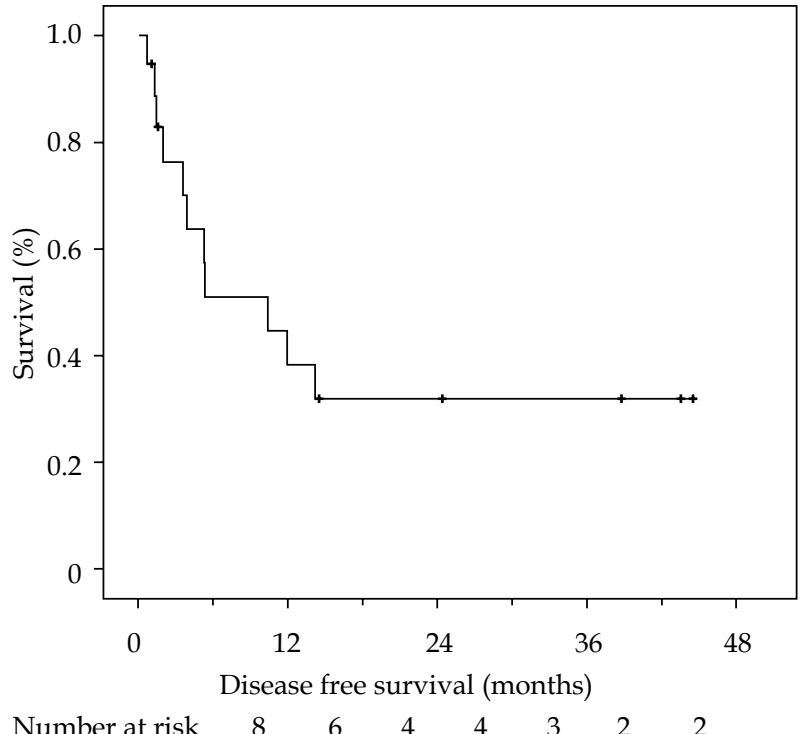

$\begin{array}{llllllll}\text { Number at risk } & 8 & 6 & 4 & 4 & 3 & 2 & 2\end{array}$

Fig. 5. Disease free survival for entire patient population $(n=18)$

Table 4. Patients with squamous cell carcinoma (SCC) and prior radiation that received ${ }^{131} \mathrm{Cs}$ implant

\begin{tabular}{ccccc}
$N$ & Median follow-up & Local control & Distant metastasis & Median time to failure \\
\hline 10 & 12.23 months & $5 / 10(50 \%)$ & $4 / 10(40 \%)$ & 3.4 months
\end{tabular}

and neck cancer is an independent prognostic factor, predicting improved LRPFS, progression-free survival (PFS), and OS [24]. Additional studies for surgical salvage with re-RT and/or CT report LRC rates ranging from 15-60\% and overall survival 5 year survival ranging from $36-60 \%$ $[28,29,30,31]$. The predominant pattern of failure in the salvage resection of head and neck cancers is local and regional recurrence [11, 32, 33, 34, 35]. A review of 22 studies by Goodwin et al. of patients who underwent surgical salvage found that the overall 2 year disease-free survival was $51.1 \%$, with individual studies reporting $75-90 \%$ of these failures due to recurrence at the primary sites or regional nodes only [14, 36, 37]. We were able to achieve comparable rates of locoregional control and survival in our study, supporting the viability of ${ }^{131}$ Cs brachytherapy as an alternative adjuvant therapy following surgical salvage.

In patients who were able to receive surgical resection, brachytherapy has been used to improve local control and overall survival with reported 2 year local control ranging from $40 \%$ to $85 \%$, and 2 year overall survival of $29 \%$ to $55 \%[17,38,39,40]$. Similar studies have investigated adjuvant brachytherapy for recurrent cancer using Ir-192 and I-125 based implants have shown benefit in improving LC [41, 42, 43]. Permanent I-125 implants have shown benefit in improving LC. Recently, Zhu et al. reported the use of I-125 brachytherapy in 19 patients as adjuvant to surgical salvage in patients with recurrent head and neck carcinomas [44]. The median LC was 24 months and the one-, two-, and three-year local control rates were $73.3 \%$, $27.5 \%$, and $27.5 \%$, respectively. We report similar rates of LRC within a similar time period of $69 \%, 62 \%$, and $52 \%$ at one, two, and three years, respectively, supporting the viability of interstitial ${ }^{131} \mathrm{Cs}$ brachytherapy as an alternative adjuvant therapy following surgical salvage.

In addition, ${ }^{131} \mathrm{Cs}$ has multiple favorable dosimetric properties compared to SBRT and ${ }^{125} \mathrm{I}$. ${ }^{131} \mathrm{Cs}$ has a higher dose rate of $0.342 \mathrm{~Gy} / \mathrm{hr}$ whereas ${ }^{125} \mathrm{I}$ has a dose rate of $0.069 \mathrm{~Gy} / \mathrm{hr}$, allowing for a greater dose to be delivered in a shorter period of time. This makes ${ }^{131} \mathrm{Cs}$ ideal for treating aggressive tumors like head and neck cancer. In addition, radiation exposure to the treating team is quite limited since $>95 \%$ radiation dose is delivered within $40-45$ days after surgical resection. This ensures increased safety for treating physician and patient's family members. A study by our institution in a series of 28 patients who received Cs-13 implants for early stage lung and recurrent H\&N cancer measured the radiation exposure to the treating physicians and staff and found that the exposure rate was acceptable [27].

Brachytherapy offers excellent local dose escalation within the tumor volume with steep dose gradients to minimize dose to the surrounding tissue, thus theoretically minimizing acute toxicity. In our study, there was a low rate of acute and chronic toxicity. This is consistent with studies that have investigated the use of brachytherapy for localized HN disease. Kupferman et al. reported in a study using ${ }^{192} \mathrm{Ir}$ and demonstrated early adverse events in $23 \%$ of patients with 3 patients experiencing grade $3 / 4$ events [45]. Other studies have demonstrated grade $3 / 4$ toxicities for head and neck brachytherapy from $7 \%$ to $26 \%[24,44,45,46]$. We found similar rates of grade $3 / 4$ events in our own series with two of our 18 patients having grade 3 toxicity. Compared to studies inves- 
tigating adjuvant EBRT after surgery, our series demonstrated lower rates of acute toxicity. Studies involving re-irradiation using adjuvant EBRT report complication rates ranging from 11 to $50 \%$ [29, 47, 48, 49].

Our study has several important limitations. First, it is based on a nonrandomized heterogeneous cohort of patients from a single institution; therefore, definitive causal inferences should not be drawn. Because toxicities were retrospectively determined based on chart review rather than prospectively collected, it is possible that not all complications were captured. Lastly, with a patient cohort of 18, a larger study with more patients is needed to fully assess the long-term complications associated with brachytherapy implantation. Nevertheless, we show here that ${ }^{131} \mathrm{Cs}$ brachytherapy may play a beneficial role in the treatment of recurrent head and neck cancer and warrants further study.

\section{Disclosure}

Isoray research funding.

Authors report no other conflict of interest.

\section{References}

1. Hall SF, Groome PA, Irish J, O'Sullivan B. The natural history of patients with squamous cell carcinoma of the hypopharynx. Laryngoscope 2008; 118: 1362-1371.

2. Bernier J, Domenge C, Ozsahin M et al. Postoperative irradiation with or without concomitant chemotherapy for locally advanced head and neck cancer. N Engl J Med 2004; 350: 19451952.

3. Cooper J, Pajak T, Forastiere AA et al. Postoperative concurrent radiotherapy and chemotherapy for high-risk squamous-cell carcinoma of the head and neck. N Engl J Med 2004; 350: 1937-1944.

4. Brockstein B, Haraf DJ, Rademaker W et al. Patterns of failure, prognostic factors and survival in locoregionally advanced head and neck cancer treated with concomitant chemoradiotherapy: a 9-year, 337-patient, multi-institutional experience. Ann Oncol 2004; 15: 1179-1186.

5. Popovtzer A, Gluck I, Chepeha DB et al. The pattern of failure after reirradiation of recurrent squamous cell head and neck cancer: implications for defining the targets. Int J Radiat Oncol Biol Phys 2009; 74: 1342-1347.

6. Wong LY, Wei WI, Lam LK et al. Salvage of recurrent head and neck squamous cell carcinoma after primary curative surgery. Head Neck 2003; 25: 953-959.

7. Wong SJ, Machtay M, Li Y. Locally recurrent, previously irradiated head and neck cancer: concurrent re-irradiation and chemotherapy, or chemotherapy alone? J Clin Oncol 2006; 24: 2653-2658.

8. McLaughlin MP, Parsons JT, Fein D et al. Salvage surgery after radiotherapy failure in T1-T2 squamous cell carcinoma of the glottic larynx. Head Neck 1996; 18: 229-235.

9. Agra IMG, Carvalho AL, Ulbrich FS et al. Prognostic factors in salvage surgery for recurrent oral and oropharyngeal cancer. Head Neck 2006; 28: 107-113.

10. Lee SC, Shores CG, Weissler MC. Salvage surgery after failed primary concomitant chemoradiation. Curr Opin Otolaryngol Head Neck Surg 2008; 16: 135-140.

11. Richey LM, Shores CG, George J et al. The effectiveness of salvage surgery after the failure of primary concomitant chemoradiation in head and neck cancer. Otolaryngol Head Neck Surg 2007; 136: 98-103.
12. Agra IMG, Carvalho AL, Pontes E et al. Postoperative complications after en bloc salvage surgery for head and neck cancer. Arch Otolaryngol Head Neck Surg 2003; 129: 1317-1321.

13. Kostrzewa JP, Lancaster WP, Iseli TA et al. Outcomes of salvage surgery with free flap reconstruction for recurrent oral and oropharyngeal cancer. Laryngoscope 2010; 120: 267-272.

14. Goodwin WJ. Salvage surgery for patients with recurrent squamous cell carcinoma of the upper aerodigestive tract: when do the ends justify the means? Laryngoscope 2000; 110: $1-18$.

15. Vermorken JB, Mesia R, Rivera F et al. Platinum-based chemotherapy plus cetuximab in head and neck cancer. N Engl J Med 2008; 359: 1116-1127.

16. Parsons JT, Mendenhall WM, Stringer SP et al. Salvage surgery following radiation failure in squamous cell carcinoma of the supraglottic larynx. Int J Radiat Oncol Biol Phys 1995; 32: 605-609.

17. Lee N, Chan K, Bekelman JE et al. Salvage re-irradiation for recurrent head and neck cancer. Int J Radiat Oncol Biol Phys 2007; 68: 731-740.

18. Strnad V, Geiger M, Lotter M et al. The role of pulsed-doserate brachytherapy in previously irradiated head-and-neck cancer. Brachytherapy 2003; 2: 158-163.

19. Strnad V, Lotter M, Kreppner S et al. Re-irradiation with interstitial pulsed-dose-rate brachytherapy for unresectable recurrent head and neck carcinoma. Brachytherapy 2014; 13: 187-195.

20. Martínez-Monge R, Valtueña G, Santisteban M et al. Time to loading and locoregional control in perioperative highdose-rate brachytherapy: The tumor bed effect revisited. Brachytherapy 2015; 14: 565-570.

21. Bartochowska A, Wierzbicka M, Skowronek J et al. High-doserate and pulsed-dose-rate brachytherapy in palliative treatment of head and neck cancers. Brachytherapy 2012;11: 137-143.

22. Bollet MA, Lapeyre M, Marchal C et al. Cervical lymph node relapses of head-and-neck squamous cell carcinoma: is brachytherapy a therapeutic option? Int J Radiat Oncol Biol Phys 2001; 51: 1305-1312.

23. Nag S, Cano ER, Demanes DJ et al. The American Brachytherapy Society recommendations for high-dose-rate brachytherapy for head-and-neck carcinoma. Int J Radiat Oncol Biol Phys 2001; 50: 1190-1198.

24. Hepel JT, Syed AMN, Puthawala A et al. Salvage high-doserate (HDR) brachytherapy for recurrent head-and-neck cancer Int J Radiat Oncol Biol Phys 2005; 62: 1444-1450.

25. Grimard L, Esche B, Lamothe A et al. Interstitial low-doserate brachytherapy in the treatment of recurrent head and neck malignancies. Head Neck 2006; 28: 888-895.

26. Puthawala A, Nisar Syed A, Gamie S et al. Interstitial lowdose-rate brachytherapy as a salvage treatment for recurrent head-and-neck cancers: long-term results. Int J Radiat Oncol Biol Phys 2001; 51: 354-362.

27. Parashar B, Wernicke AG, Pavese A et al. Cesium-131 permanent seed brachytherapy: dosimetric evaluation and radiation exposure to surgeons, radiation oncologists, and staff. Brachytherapy 2011; 10: 508-513.

28. Salama JK, Vokes EE, Chmura SJ et al. Long-term outcome of concurrent chemotherapy and reirradiation for recurrent and second primary head-and-neck squamous cell carcinoma. Int J Radiat Oncol Biol Phys 2006; 64: 382-391.

29. Machtay M, Rosenthal DI, Chalian AA et al. Pilot study of postoperative reirradiation, chemotherapy, and amifostine after surgical salvage for recurrent head-and-neck cancer. Int J Radiat Oncol Biol Phys 2004; 59: 72-77.

30. De Crevoisier R, Domenge C, Wibault P et al. Full dose reirradiation combined with chemotherapy after salvage surgery in head and neck carcinoma. Cancer 2001; 91: 2071-2076. 
31. Chua DT, Sham JS, Hung KN et al. Salvage treatment for persistent and recurrent T1-2 nasopharyngeal carcinoma by stereotactic radiosurgery. Head Neck 2001; 23: 791-798.

32. Watson JC, Ridge JA. Surgical management of local and regional recurrent head and neck squamous cell carcinoma. Curr Opin Oncol 1998; 10: 207-212.

33. Gilbert H, Kagan AR. Recurrence patterns in squamous cell carcinoma of the oral cavity, pharynx, and larynx. J Surg Oncol 1974; 6: 357-380.

34. Shah JP, Cendon RA, Farr HW et al. Carcinoma of the oral cavity. Factors affecting treatment failure at the primary site and neck. Am J Surg 1976; 132: 504-507.

35. Kearney PL, Watkins JM, Shirai K et al. Salvage resection for isolated local and/or regional failure of head/neck cancer following definitive concurrent chemoradiotherapy case series and review of the literature. Mcgill J Med 2011; 13: 29.

36. Decroix Y, Ghossein NA. Experience of the Curie institute in treatment of cancer of the mobile tongue. I. Treatment policies and result. Cancer 1981; 47: 496-502.

37. Razack MS, Sako K, Patel JK. The role of initial modality in treatment of squamous cell carcinoma of the tongue. J Surg Oncol 1982; 19: 136-138.

38. Park RI, Liberman FZ, Lee DJ et al. Iodine- 125 seed implantation as an adjunct to surgery in advanced recurrent squamous cell cancer of the head and neck. Laryngoscope 1991; 101: 405-410.

39. Morikawa LK, Zelefsky MJ, Cohen GN et al. Intraoperative high-dose-rate brachytherapy using dose painting technique: evaluation of safety and preliminary clinical outcomes. Brachytherapy 2013; 12: 1-7.

40. Vikram B, Strong EW, Shah JP et al. Intraoperative radiotherapy in patients with recurrent head and neck cancer. Am J Surg 1985; 150: 485-487.

41. Narayana A, Cohen GN, Zaider M et al. High-dose-rate interstitial brachytherapy in recurrent and previously irradiated head and neck cancers - preliminary results. Brachytherapy 2007; 6: 157-163.

42. Glatzel M, Büntzel J, Schröder D et al. High-dose-rate brachytherapy in the treatment of recurrent and residual head and neck cancer. Laryngoscope 2002; 112: 1366-1371.

43. Jiang YL, Meng N, Wang JJ et al. CT-guided iodine-125 seed permanent implantation for recurrent head and neck cancers. Radiat Oncol 2010; 5: 68.

44. Zhu L, Jiang Y, Wang J et al. An investigation of 125I seed permanent implantation for recurrent carcinoma in the head and neck after surgery and external beam radiotherapy. World J Surg Oncol 2013; 11: 60.

45. Kupferman ME, Morrison WH, Santillan AA et al. The role of interstitial brachytherapy with salvage surgery for the management of recurrent head and neck cancers. Cancer 2007; 109: 2052-2057.

46. Syed AM, Puthawala AA, Damore SJ et al. Brachytherapy for primary and recurrent nasopharyngeal carcinoma: 20 years' experience at Long Beach Memorial. Int J Radiat Oncol Biol Phys 2000; 47: 1311-1321.

47. Spencer SA, Harris J, Wheeler RH et al. Final report of RTOG 9610, a multi-institutional trial of reirradiation and chemotherapy for unresectable recurrent squamous cell carcinoma of the head and neck. Head Neck 2008; 30: 281-288.

48. Janot F, de Raucourt D, Benhamou E et al. Randomized trial of postoperative reirradiation combined with chemotherapy after salvage surgery compared with salvage surgery alone in head and neck carcinoma. J Clin Oncol 2008; 26: 5518-5523.

49. Langer CJ, Harris J, Horwitz EM et al. Phase II study of lowdose paclitaxel and cisplatin in combination with split-course concomitant twice-daily reirradiation in recurrent squamous cell carcinoma of the head and neck: results of Radiation Therapy Oncology Group Protocol 9911. J Clin Oncol 2007; 25: 4800-4805. 